\title{
PROBABILISTIC EVALUATIONS OF ECONOMIC MERIT OF WATER RESOURCE PROJECTS
}

\author{
Yeou-Koung Tung \\ and \\ Jinn-Chuang Yang \\ Journal Article $1994 \quad$ WWRC-94-23
}

In

Water Resources Management

Volume 8

\author{
Yeou-Koung Tung \\ Wyoming Water Resources Center \\ and \\ Statistics Department \\ University of Wyoming \\ Laramie, Wyoming \\ Jinn-Chuang Yang \\ Department of Civil Engineering \\ National Chiao-tung University \\ Hsinchu,Taiwan, \\ Republic of China
}




\title{
Probabilistic Evaluations of Economic Merit of Water Resource Projects
}

\author{
YEOU-KOUNG TUNG \\ Wyoming Water Resources Center and Statistics Department, University of Wyoming, Laramie, \\ WY 82071, U.S.A. \\ and
}

JINN-CHUANG YANG

Department of Civil Engineering, National Chiao-tung University, Hsinchu, Taiwan, Republic of China

(Received: 18 February 1994)

\begin{abstract}
The presence of uncertainties in assessing benefits and costs detracts from deterministic economic evaluation. This paper examines three probabilistic economic evaluation procedures: stochastic dominance, expected gain-confidence limit, and Hurwicz criterion. Their relative performances are evaluated through an example. Furthermore, the paper investigates the effects of (1) distributional assumptions of benefit and cost items, (2) uncertainty in project life, and (3) distribution of net present value on the project selection.
\end{abstract}

Key words: uncertainty, probabilistic analysis, economic analysis

\section{Introduction}

Economic analysis has been applied to assess the differences among projects and to provide a basis for project comparison. Among the various economic performance criteria, $B / C$ ratio $(B C)$ and net present value (NPV) are perhaps the most commonly used criteria to evaluate the economic merit of competitive public projects. Canada and White (1980) proposes three criteria to judge the economic feasibility of alternatives (projects) without uncertainty: (1) the net present value of a project is nonnegative; (2) the project rate-of-return (ROR) exceeds the specified minimum ROR; and (3) the B/C ratio exceeds 1 . To yield a consistent result between the two criteria, the incremental $\mathrm{B} / \mathrm{C}$ analysis should be implemented.

The criteria mentioned above for testing the feasibility of projects and for projects prioritization are intuitively sensible and theoretically valied for cases without uncertainty. As the uncertainties are embedded in benefits and costs of a water resource project, the values of NPV and B/C cannot be know exactly. In the presence of uncertainty, there exists a probability for NPV of any water resource project to be negative. Also, there is a possibility that the NPV of one project is larger than the other or vice versa. The uncertainty of NPV or B/C ratio creates difficulty in using the criteria and rules mentioned above for project evaluation.

When benefits and costs are random, the derivation of statistical properties of economic performance criteria such as the NPV or B/C ratio is the first step for 
assessing the feasibility and prioritization of projects. The uncertainty characteristics of a random variable can be described by its PDF and/or by its statistics such as their moments. Probabilistic evaluations incorporate uncertainty characteristics, along with economic principles, to compare the merits of various competitive projects.

In Section 2, a brief discussion on the decision-maker's risk attitude and their effects on project evaluation is given. Then, Sections 3, 4, and 5 describe, respectively, the theoretical background of the three probabilistic economic methods followed by outlines of proposed evaluation procedures in Section 6 based on the probabilistic approaches. In Section 7, applications of the probabilistic approaches to an example are presented to demonstrate their utilities and to examine their relative performances.

\section{Probabilistic Project Evaluation and Risk Attitudes}

Consider using the economic NPV criterion subject to uncertainty. Probabilistic economic evaluation under uncertainty requires knowledge about the statistical properties of NPV. The frequently used statistical properties of uncertain project return are the mean and variance.

Using mean and variance values for project comparison is a rather common practice in dealing with uncertain returns. A classical mean-variance $(\mathrm{E}-\mathrm{V})$ criterion was first proposed by Markowitz (1959) for portfolio selection. In some situations, using the expected return and the associated variance cannot account for the full extent of uncertainty of project return. This was elaborated recently by Tung $e t a l$. (1993). They indicates that, in project selection and evaluation under uncertainty, the use of complete statistical information of economic performance criteria, carried by the distribution function, rather than the first two moments, is necessary.

Three types of risk attitude are common: risk-aversion, risk-neutral, and risktaking. For most public investment decision-makers, the fear of possible failure of an intended project performance caused by uncertainties frequently translates into a more cautious and conservative attitude. The use of a safety factor in many engineering designs is an example of this behavior. It is analogous to an individual's action in purchasing insurance to protect against unexpected catastrophes. This conservative attitude when faced with uncertainty and risk, is known as risk aversion. For a risk-averse decision-maker, the utility function associated with the random return, which indicates the decision-maker's preference for different levels of return, is increasing and concave. Because such a risk-averse attitude generally prevails in many public project investments including water resources project design and planning, the proposed project evaluation procedure presented in this paper will make such assumption. Detail discussions of various risk attitude can be found in Tung et al. (1993) and references cited therein. 


\section{Criterion Based on Stochastic Dominance}

The concept of stochastic dominance has been applied to the area of finance for portfolio selection problems (Porter and Carey, 1974; La Cava, 1976). For an expected-utility maximizing decision-maker, assume that his/her utility (or preference level) increases as the attribute, $y$, increases. This attribute in project evaluation might be any economic performance measure, such as BC or NPV. Project 1 dominates projet 2 if the probability density function (PDF) of project $1, f_{1}(y)$, dominates that of project $2, f_{2}(y)$. This is called the dominance conditions (Bunn, 1984). Detail discussions of the stochastic dominance and its application to water resource project evaluation can be found in Tung et al. (1993). The following provides a thumb-nail sketch of the procedure.

In theory, the stochastic dominance test can be performed to any degree involving multiple integrals of the difference in the cumulative distribution functions (CDFs) of the economic performance measure for the projects under consideration. In practice, the first three degrees of stochastic dominance test are used; higher levels stochastic dominance do not provide much plausible justification for risk attitude.

In the first-degree stochastic dominance (FSD) test, no risk attitude of any type is assumed. The basic assumption is that a decision-maker prefers more of the attributes, $y$, to less. The FSD states that the project $j$ dominates project $i$ if

$$
\delta F_{i-j}^{1}(y)=\int_{-\infty}^{y}\left[f_{i}(z)-f_{j}(z)\right] \mathrm{d} z=F_{i}(y)-F_{j}(y) \geq 0
$$

for all attribute levels $y$ with strictly inequality for some $y$ in which $F_{x}$ represents the CDF of the economic measure for project $x$. In the case that the FSD test is indecisive, the two projects are nondominant or efficient. Then, the relative preference of the two projects can further be tested by the second-degree stochastic dominance (SSD) criterion. In the SSD test, the procedure further assumes that the decision-maker is risk-averse. Based on the SSD test, project $j$ dominates project $i$ if

$$
\delta F_{i-j}^{2}(y)=\int_{-\infty}^{y}\left[F_{i}(z)-F_{j}(z)\right] \mathrm{d} z=\int_{-\infty}^{y} \delta F_{i-j}^{1}(z) \mathrm{d} z \geq 0
$$

for all attribute levels $y$ with strict inequality hold for some $y$. The SSD test involves an evaluation of integration of CDF of the two project returns under consideration.

Again, if the SSD test is indecisive, the third-degree stochastic dominance (TSD) test can be conducted which further assumes that the risk-aversion of a decision-maker diminishes as the return gets larger and the attitude toward risk could not drastically change from risk-aversion to risk-taking. The decision rule of the TSD test is that project $j$ dominates project $i$ if and only if $E\left(Y_{j}\right) \geq E\left(Y_{i}\right)$, and 
TABLE I. Paradox of Markowitz E-V criterion

\begin{tabular}{llllr}
\hline Project & $\mu$ & $\sigma \mathrm{N}$ & $\mu+\sigma$ & $\mu-\sigma$ \\
\hline A & 150 & 20 & 170 & 130 \\
B & 110 & 15 & 125 & 95 \\
\hline
\end{tabular}

$$
\begin{aligned}
\delta F_{i-j}^{3}(y) & =\int_{-\infty}^{y}\left[\int_{-\infty}^{z}\left[F_{i}\left(z^{\prime}\right)-F_{j}\left(z^{\prime}\right)\right] \mathrm{d} z^{\prime}\right] \\
& =\int_{-\infty}^{y} \delta F_{i-j}^{2}(z) \mathrm{d} z \geq 0
\end{aligned}
$$

for all values of the attribute $y$.

\section{Criterion Based on Expected Gain-Confidence Limit (EG-CL)}

In the EG-CL method, the risk is the probability that the return would fall below a lower confidence limit. The lower confidence limit defines the floor prospective return below which damaging effects may occur. The method is based on Baumol's (1963) correction to the Markowitz E-V criterion (1952). The method is later extended by El-Ramly et al. (1975) who further incorporate the EG-CL criterion into the framework of decision theory.

The Markowitz E-V criterion states that preference is given to the investment having a minimum variance of return, if the expected returns are equal, or to the investment with a maximum expected return, if the variances of returns are equal. The investments that cannot be eliminated by the criterion are efficient, nondominant, or admissible.

However, the Markowitz E-V criterion has a paradox which can be observed from Table I. By Markowitz E-V criterion, projects A and B are efficient. If one considers that the high and low plausible returns can be represented by $\mu+\sigma$ and $\mu$ $-\sigma$, respectively. Then, most decision-makers would regard project $A$ dominates project $B$ because the low plausible return of project $A, \mu_{A}-\sigma_{A}$, is higher than the high plausible return of project $\mathrm{B}, \mu_{B}+\sigma_{B}$.

To resolve the paradox of Markowitz E-V criterion, Baumol (1963) proposed the EG-CL criterion which states that project A dominate project B if $\mu_{A} \geq \mu_{B}$ and $\mu_{A}-\lambda \sigma_{A} \geq \sigma_{B}-\lambda \sigma_{B}$, for a suitably chosen $\lambda$ and without both equalities simultaneously. The sign of $\lambda$ indicates the risk attitude of a decision-maker. For a risk-averse decision-maker, $\lambda$ is positive-valued; for risk-neutral, $\lambda$ is zero; for risk-taking, $\lambda$ is negative-valued. The larger the positive value of $\lambda$, the more conservative the decision-maker will be. When the value of $\lambda$ is very large, the Markowitz E-V criterion and the Baumol EG-CL criterion would yield the identical efficient set. The following discussions will base on the assumption that decisionmakers are risk-averse. 
TABLE II. Types of error in decision-making

\begin{tabular}{lll}
\hline & \multicolumn{2}{l}{ State of decision-maker's Risk-Averse } \\
\hline Decision & $\lambda<\lambda_{b}$ & $\lambda \geq \lambda_{b}$ \\
\hline A dom B & Correct decision & Type I error \\
A dom B & Type II error & Correct decision \\
\hline
\end{tabular}

Using the EG-CL criterion in the framework of decision theory, the expected loss due to incorrectt action is used as the basis for project evaluation. If $\mu_{\mathrm{A}}>\mu_{\mathrm{B}}$ and $\sigma_{\mathrm{A}}<\sigma_{\mathrm{B}}$, project $\mathrm{A}$ dominates project $\mathrm{B}$ by the EG-CL criterion because $\mu_{\mathrm{A}}-$ $\lambda \sigma_{\mathrm{A}}>\mu_{\mathrm{B}}-\lambda \sigma_{\mathrm{B}}$ for all positive-valued $\lambda$. This result is identical to the Markowitz $\mathrm{E}-\mathrm{V}$ criterion. In cases that $\mu_{\mathrm{A}}>\mu_{\mathrm{B}}$ and $\sigma_{\mathrm{A}} \geq \sigma_{\mathrm{B}}$, project $\mathrm{A}$ will dominates project $\mathrm{B}$ only for some $\lambda$. A break-even value for $\lambda_{\mathrm{b}}>0$ can be determined by solving

$$
\mu_{\mathrm{A}}-\lambda_{b} \sigma_{\mathrm{A}}=\mu_{\mathrm{B}}-\lambda_{b} \sigma_{\mathrm{B}}
$$

resulting in $\lambda_{\mathrm{b}}=\left(\mu_{\mathrm{A}}-\mu_{\mathrm{B}}\right) /\left(\sigma_{\mathrm{A}}-\sigma_{\mathrm{B}}\right)$. Then, decision rule is that project $\mathrm{A}$ dominates project $B$ (denoted as $A \succ B$ ) if the decision-maker's state $\lambda$ is less than $\lambda_{b}$; whereas the two projects $A$ and $B$ are efficient (denoted as $A \nsucc B$ ) if $\lambda \geq \lambda_{b}$. In the framework of decision theory, the effect of random project returns on the decision is translated into decision-maker's degree of risk-aversion represented by the value of $\lambda$ (El-Ramly et al., 1975).

The decisions and the decision-maker's state of risk-averseness (represented by the value of $\lambda$ ) can be shown as Table II. A decision-maker might commit two types of error: (1) Type-I error associated with the decision 'A $\succ$ B' given that the decision-maker's state of risk-averseness is $\lambda \geq \lambda_{b}$; and (2) Type-Il error associated with the decision ' $\mathrm{A} \nsucc \mathrm{B}$ ' given $\lambda<\lambda_{\mathrm{b}}$. Associated with each type of error, there is an opportunity loss which can be computed as, for Type-I error,

$$
\begin{aligned}
L_{\mathrm{A} \succ \mathrm{B}} & =G_{B}(\lambda)-G_{A}(\lambda)=\left(\mu_{\mathrm{B}}-\lambda \sigma_{\mathrm{B}}\right)-\left(\mu_{\mathrm{A}}-\lambda \sigma_{\mathrm{A}}\right), \quad \text { for } \lambda \geq \lambda_{\mathrm{b}}, \\
& =0, \text { elsewhere, }
\end{aligned}
$$

and for Type-II error,

$$
\begin{aligned}
L_{\mathrm{A} \nsucc \mathrm{B}} & =G_{A}(\lambda)-G_{B}(\lambda)=\left(\mu_{\mathrm{A}}-\lambda \sigma_{\mathrm{A}}\right)-\left(\mu_{\mathrm{B}}-\lambda \sigma_{\mathrm{B}}\right), \quad \text { for } \lambda<\lambda_{\mathrm{b}}, \\
& =0, \text { elsewhere, }
\end{aligned}
$$

in which $G_{A}(\lambda)=\mu_{\mathrm{A}}-\lambda \sigma_{\mathrm{A}}$ and $G_{B}(\lambda)=\mu_{B}-\lambda \sigma_{B}$. Due to the uncertain nature of $\lambda$, the expected opportunity loss associated with the Type-I error for the decision ' $\mathrm{A} \succ \mathrm{B}$ ' can be calculated as

$$
E\left(L_{\mathrm{A} \nsucc \mathrm{B}}\right)=\int_{\lambda_{\mathrm{b}}}^{\infty}\left[G_{B}(\lambda)-G_{A}(\lambda)\right] f(\lambda) \mathrm{d} \lambda
$$




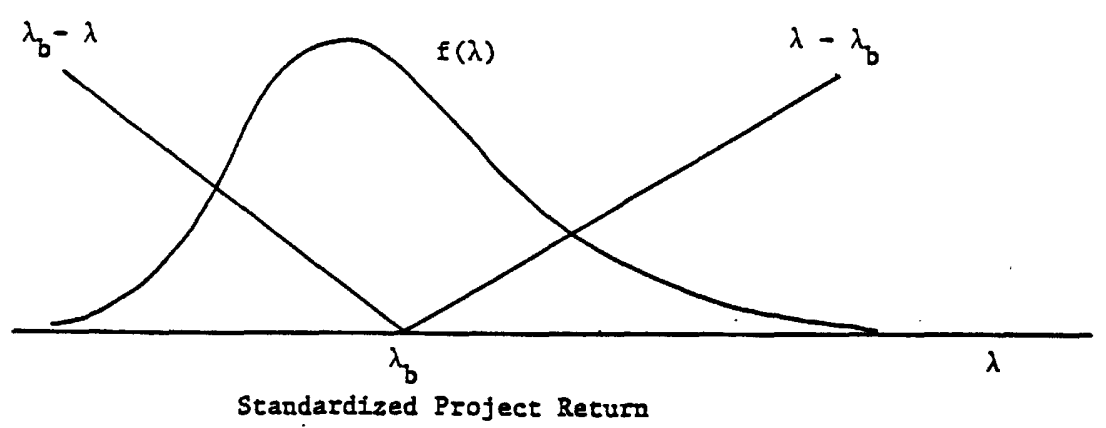

Fig. 1. Computation of the expected opportunity loss.

$$
=\left(\sigma_{\mathrm{A}}-\sigma_{\mathrm{B}}\right)\left[\mu_{\mathrm{u}\left(\lambda, \lambda_{\mathrm{b}}\right)}-\lambda_{\mathrm{b}}\left(1-F\left(\lambda_{\mathrm{b}}\right)\right)\right]
$$

in which $f(\lambda)$ and $F(\lambda)$ are the PDF and CDF of $\lambda$, respectively, and the term $\mu_{\mathrm{u}(\lambda, \lambda \mathrm{b})}$ is called the upward partial-moment of the first-order (Buck and Askin, 1986). Similarly, the expected opportunity loss associated the Type-II error with ' $\mathrm{A} \nsucc \mathrm{B}$ ' is

$$
\begin{gathered}
E\left(L_{\mathrm{A} \nsucc \mathrm{B}}\right)=\int_{0}^{\lambda_{\mathrm{b}}}\left[G_{A}(\lambda)-G_{B}(\lambda)\right] f(\lambda) \mathrm{d} \lambda \\
=\left(\sigma_{\mathrm{A}}-\sigma_{\mathrm{B}}\right) \int_{0}^{\lambda_{\mathrm{b}}}\left(\lambda_{\mathrm{b}}-\lambda\right) f(\lambda) \mathrm{d} \lambda
\end{gathered}
$$

Figure 1 shows the schematic diagram for computing the expected opportunity loss. Since $\lambda$ represents the number of units of standard deviation from the mean project return, it in effect represents the standardized random project return. Evaluations of the expected opportunity losses by Equations (7) and (8), in general, require carrying out numerical integration. However, for a normally distributed project return, $\lambda$ has a standard normal distribution. Under the normality condition, Equations (7) and (8) can be expressed, respectively, as

$$
\begin{aligned}
& E\left(L_{\mathrm{A} \succ \mathrm{B}}\right)=\left(\sigma_{\mathrm{A}}-\sigma_{\mathrm{B}}\right)\left[\phi\left(\lambda_{\mathrm{b}}\right)-\lambda_{\mathrm{b}}\left(1-\Phi\left(\lambda_{\mathrm{b}}\right)\right)\right], \\
& E\left(L_{\mathrm{A} \succ \mathrm{B}}\right)=\left(\sigma_{\mathrm{A}}-\sigma_{\mathrm{B}}\right)\left[\lambda_{\mathrm{b}}\left(\Phi\left(\lambda_{\mathrm{b}}\right)-0.5\right)+\phi\left(\lambda_{\mathrm{b}}\right)-\phi(0)\right]
\end{aligned}
$$

in which $\phi(\lambda)$ and $\Phi(\lambda)$ are, respectively, the PDF and CDF of the standard normal random variable. Based on the expected opportunity loss, the decision rule is

(1) Select project $A$ if $E\left(\mathrm{~L}_{\mathrm{A}} \succ B\right)<\mathrm{E}\left(\mathrm{L}_{\mathrm{A}} \nsucc B\right)$; or

(2) Retain both projects $\mathrm{A}$ and $\mathrm{B}$ if $\mathrm{E}\left(\mathrm{L}_{\mathrm{A}} \succ B\right) \geq \mathrm{E}\left(\mathrm{L}_{\mathrm{A}} \nsucc B\right)$. 


\section{Criterion Based on Hurwicz Criterion}

The Hurwicz is popular in risk analysis for decision-making problems. This criterion represents a range of attitudes from the most optimistic to the most pessimistic (Taha, 1982). The Hurwicz criterion weighs the lower and upper bounds of two projects by the respective weights $H_{\alpha i j}$ and $\left(1-H_{\alpha i j}\right)$ where $0 \leq H_{\alpha i j} \leq 1$. The value of $H_{\alpha i j}$ is calculated by solving the following equation

$$
\left(1-H_{\alpha i j}\right) L_{i}+H_{\alpha i j} U_{i}=\left(1-H_{\alpha i j}\right) \dot{L_{j}}+H_{\alpha i j} U_{j}
$$

where $L_{i}$ and $U_{i}$ are, respectively, the most pessimistic and the most optimistic values of the performance index of project $i$. In this study, $L_{i}$ and $U_{i}$ are related to the lower and upper quantiles of the project performance index $Y_{i}$ for the project $i$. The values of $L_{i}$ and $U_{i}$ can be determined by corresponding them to the tail areas of the associated PDF of project return.

On the basis of lower and upper limits for project return, the Hurwicz criteria to determine the relative preference between projects $i$ and $j$ are the following:

(1) If $L_{i} \geq L_{j}$ and $U_{i}$ and $U_{i} \geq U_{j}$ with not both equalities holding simultaneously, then project $i$ dominates project $j$.

(2) If $L_{i} \geq L_{j}$ and $U_{i} \leq U_{j}$ with not both equalities holding simultaneously, then the two projects $i$ and $j$ are efficient.

This decision rules are entirely based on the relative positions of the lower and upper limits of uncertain returns from two projects under consideration. For further evaluation of projects in efficient set, decision-maker's risk attitude can be incorporated.

To determine which project is optimal, decision-makers must rate their preference towards optimism (or pessimism) on a scale of 0 to 1 . A preference rating of 0 indicates a complete pessimism, a preference rating of 0.5 indicates an absence of strong feeling one way or the other, and a preference rating of 1 indicates a total optimism.

Comparing a pair of projects, the region from 0 to $\mathrm{H}_{\alpha i j}$ is donated by the alternative with a greater lower bound while the region from $\mathrm{H}_{\alpha i j}$ to 1 is donated by the projects with a greater upper bound. Therefore, the decision rule to determine the preference between project $i$ and project $j$ is the following: The project dominating the region in which the decision-maker's preference rating lies is the optimal project.

When more than two projects are involved, say $m>2$, the Hurwicz $\alpha$ is compute for all possible ${ }_{m} \mathrm{C}_{2}=m(m-1) / 2$ pairs. As a result, these ${ }_{m} C_{2}$ Hurwicz- $\alpha$ values divide the range $[0,1]$ into $m C_{2}+1$ segments. A single preferred project in a particular segment, then, is the one that has exactly $(m-1)$ appearances in the ${ }_{m} C_{2}$ Hurwicz pairs. An illustration of the idea for a fourproject case is shown in Figure 2. If the maximum number of appearances of an project in a particular segment is $m-k$, there will exist $m-(m-k)=k$ projects that will be equally desirable in the segment (see Figure 3). 


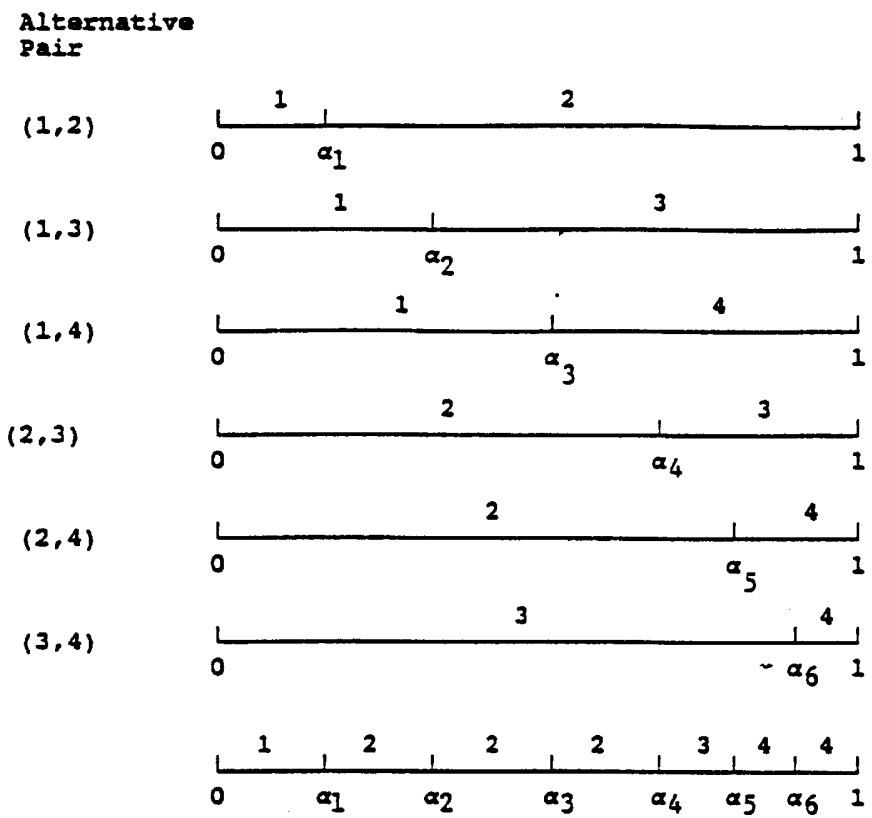

Fig. 2. A single preferred alternative in each segment for the four alternatives case.

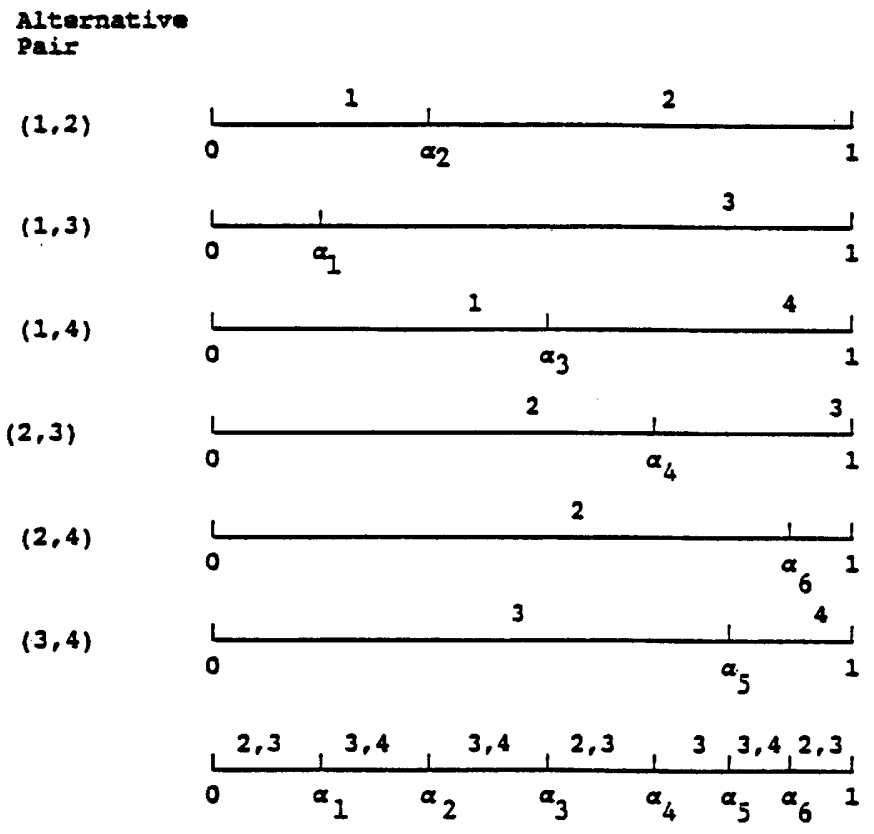

Fig. 3. Multiple preferred alternatives in some segments for the four alternatives case. 


\section{Proposed Project Evaluation Procedures}

This section describes the procedures for probabilistic evaluation of project economic merit based on the aforementioned concepts of stochastic dominance, expected gain-confidence limit, and Hurwicz criterion. In principle, the proposed probabilistic evaluation procedures consist of a preliminary screening to filter out those inferior projects unworthy of further consideration and to reduce the number of projects that are probabilistic compatible. After the preliminary screening, those projects remained are subject to further scrutiny during which the decision-makers will bring about their attitude toward risks in evaluating the projects.

\subsection{PROCEDURE BASED ON STOCHASTIC DOMINANCE}

The proposed procedure using the concept of stochastic dominance as the core elements includes the following five steps.

Step 1. (Feasibility Test) - A project is considered feasible if the mean value of the NPV is nonnegative. The requirement of nonnegative expected NPV ensure that the aggregate cost for the project can be, at least in the long run, recovered by the aggregate benefit. The decision rule at this step is to eliminate those projects with negative expected NPV from further consideration.

Step 2. (FSD Test) - For those projects passing the feasibility test, the FSD test is conducted according to Equation (1). When the FSD test is indecisive and several projects are remained efficient, the SSD test is performed to resolve this dilemma.

Step 3. (SSD Test) - To carry out the SSD test, Equation (2) is applied for all possible values of NPV based on which decision is made about whether the two projects under consideration are efficient or one project dominates the other. When a definite conclusion cannot be made, the TSD test can be applied to further evaluation if the decision-maker desires.

Step 4. (TSD Test) - With an assumption of decreasing risk-aversion behavior of a decision-maker, Equation (3) is used over all possible values of NPV for indication about the relative dominance between the two projects.

Step 5. (Final test)-To ensure that the remaining projects, after steps $1-4$ screening, would yield a certain desirable level of outcome, an evaluation of the probability to achieve the specified threshold value is made as

$$
\operatorname{Pr}\left(\mathrm{NPV} \geq \mathrm{NPV}^{\circ}\right) \geq \alpha
$$

where $\operatorname{Pr}($.$) represents the probability, \mathrm{NPV}^{\circ}$ is the specified threshold values for the NPV, and $\alpha$ is the minimum acceptable probability beyond $\mathrm{NPV}^{\circ}$. The 
minimum acceptable probability $\alpha$ and the threshold value of NPV ${ }^{\circ}$ are subjectively determined by the decision-maker depending on his/her level of expectation. The larger are the values of $\alpha$ od NPV ${ }^{\circ}$, the higher the expectation of the decision-maker has about the performance of the project.

It is possible that proposed evaluation procedure might result in several projects remained after the first four screening steps. The final step is also useful for the circumstance in which the projects under consideration are mutually exclusive, i.e., only one project can be chosen for implementation To home-in the most economically efficient project further, the decision-maker can manipulate the level of expectation indicated by $\mathrm{NPV}^{\circ}$ and/or $\alpha$ until one is left. Alternatively, the home-in procedure can be made by computing the probability of one project being better than the others. The decision can be made by the following rule:

$$
\text { If } \operatorname{Pr}\left(\mathrm{NPV}_{i}>\mathrm{NPV}_{j}\right)\left\{\begin{array}{l}
>0.5, \text { reject project } j \\
<0.5, \text { reject project } i
\end{array}\right.
$$

For the random NPV having a normal distribution, the above rule reduces to simply compare the mean values of the NPV and choose the project with a larger mean NPV. For other non-normal distributions, computation of probability would have to be carried out.

\subsection{PROCEDURE BASED ON EG-CL CRITERION}

Project evaluation on the basis of the EG-CL criterion can be performed as the following

Step 1. (Feasibility Test) - Same as the stochastic dominance procedure.

Step 2. (Markowitz E-V Test) - For those projects remained from the feasibility test, select a pair of projects $i$ and $j$ and compare their respective means and standard deviation of the NPV. Project $i$ dominates if $\mu_{i} \geq \mu_{j}$ and $\mu_{i} \leq \sigma_{j}$, with not both equalities holding simultaneously. The project dominated by the Markowitz $\mathrm{E}-\mathrm{V}$ criterion is removed from further consideration. This step is repeated for all possible pairs of candidate projects.

Step 3. (Expected Opportunity Loss Test) - For those project remained after Step 2 test, select a pair of projects for which the break-even $\lambda_{b}$ is computed by Equation (4). Then, the expected opportunity losses associated with the two types of error are computed by Equations (7) and (8). The decision can accordingly be made based on the values of the expected opportunity losses. This step is repeated for all possible pairs of candidate projects. 
Step 4. (Final Test) - The same as the final test as described in stochastic dominance procedure.

\subsection{PROCEDURE BASED ON HURWICZ CRITERION}

Project evaluation procedure using Hurwicz criterion consists of four steps as the following:

Step 1. (Feasibility Test) - Same as the stochastic dominance procedure.

Step 2. - For all projects remained after the feasibility test, compute the most pessimistic and optimistic values of the performance index for each project under consideration. Remove those dominated project whose pessimistic and optimistic values are simultaneously lower than at least one candidate project.

Step 3. - For the projects remained after Step 2 test, determine the Hurwicz- $\alpha$ value for all possible pairs using Equation (11). Determine the range of interval for $\alpha$ in $(0,1)$ and the corresponding project within which the project dominates. Decision-maker select the appropriate project(s) according to his/her degree of risk-aversion with 0 being totally conservative and 1 being totally optimistic.

Step 4. - The same as the final test as described in stochastic dominance procedure.

\section{Applications}

To demonstrate and evaluate the methodologies, the proposed probabilistic economic evaluation framework was applied to Cache la Poudre River basin development in Colorado. The problem is concerned with the rapid urban growth in the midst of an irrigation-based agricultural economy. Additional water for the future development of the Cache la Poudre River basin in northern Colorado is needed. The goals of the project are to develop available water supplies and power in the basin. A reconnaissance-level engineering study was completed in 1983 by to Tudor Engineering company. Eight alternatives were proposed for project implementation. Since the estimated component benefits and costs in the original data for each alternative were given as single-valued, they are herein considered as the 'most-likely' values (Grigg, 1985). Giving different subjective uncertainty factors for the benefit and cost components, the 'pessimistic' and the 'optimistic' values are obtained by multiplying uncertainty factors to the corresponding the most-likely values. The data set used in this application is presented in Table III. Two types of cash flow patterns are used for each of the benefit and cost items (see Figure 4).

It is understood that the present value of project net benefit is a function of project life, construction period, interest rate, and cash flow patterns of benefits 
Oniform

Benerft Items:

Hydropower

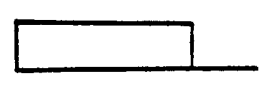

Run-of-the-River Energy

Water Supply

Irrigation

Improved

Management

cost Items:

Construction

Operation 8

Maintenance
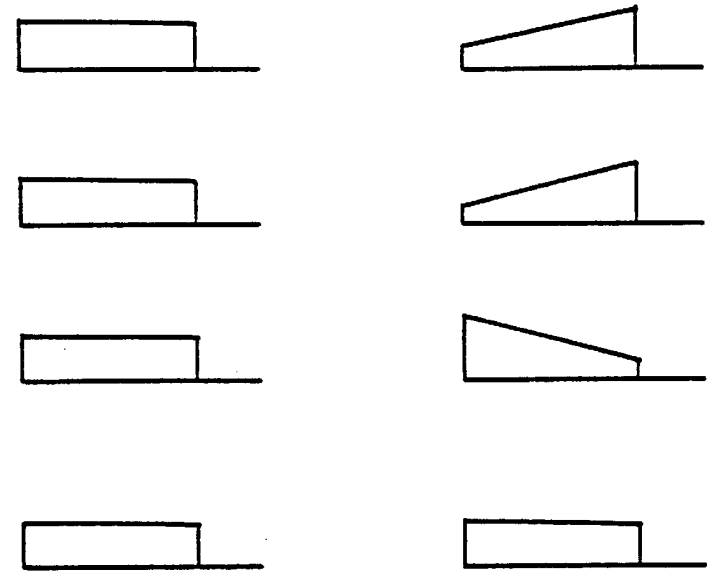

Fig. 4. Types of cash flow patterns considered for benefit and cost items.

and costs. In this application, the benefit and cost parameters, along with the project life, were treated as random variables. There are several articles dealing with the project life uncertainty in probabilistic economic analysis (Barns et al., 1978; Bey, 1981; Chen and Manes, 1986; Tufekci and Yong, 1987; Van Horne, 1972; Young and Contreras, 1975).

To facilitate the analysis in the continuous discounting framework, the annual interest rate of $i=6 \%$ is converted to its nominal discount rate of $r=\ln (1+i)=5.8 \%$. Three economic evaluation procedures, namely, stochastic dominance (SD) tech- 
nique, expected gain-confidence limit (EG-CL) method, and Hurwicz- $\alpha$ method were used for purpose of examining the relative performance of the different evaluation procedures. Furthermore, to examine the effect of probability distributions of benefit and cost parameters and that of project life, different distributions were used in the analysis. More specifically, normal, lognormal, gamma, Weibull, beta, and triangular distributions were used for benefit and cost parameters whereas uniform, normal, and triangular distributions are used for random project life.

The purposes of this application are: (1) to examine the effect of project life uncertainty on the evaluation result; (2) to examine and compare the performance of the proposed evaluation and screening procedure; (3) to investigate the effect of probability distribution for NPV on the evaluation results; and (4) to investigate the sensitivity of the evaluation results to the distributions of benefit and cost components.

The uncertainties associated with the benefit and cost items in each of the eight alternatives for the Cache la Poudre River basin development are listed in Table III. Also, the nominal project life for each of the alternative is given by Grigg (1985). To examine the effect of project life uncertainty on the evaluation of expected net nebefit and its associated variance, these nominal project lifes are treated as the most likely values. The project life uncertainty is artificially imposed in this study and is shown in Table III.

Table IV contains the expected values and variances of the net present value for Alternative 2 to Alternative 7 under the following conditions: (1) $t_{o}=0$ for initial capital outlay; (2) all annual benefit and cost items have horizontal type of cash flow pattern; and (3) project life $T$ is uncertain with a triangular distribution. The category of $\Omega_{T}=5.4 \%$ represents that the coefficient of variation of project life is $5.4 \%$, whereas $\Omega_{T}=0$ represents the project life is a constant without uncertainty. Consistently, the consideration of project life uncertainty results in a slight decrease in the expected net present value (as indicated by Chen and Manes, 1986) and an increase in the standard deviation.

Table Va-f show the expectation and variance of net benefit for different alternatives under the conditions of with and without considering project life uncertainty using different distributional assumptions. The percentage changes of expectation and variance of net benefit without project life uncertainty over those with uncertainty are shown in the last block. In addition to the similar behavior as shown in Table IV, the difference in estimated expectation and variance of net benefit with and without project life uncertainty increases as the uncertainty of project life gets larger.

Tables VI and VII contain the final selected project by different evaluation procedures and distributions for net benefit and project life using uniform and nonuniform cash flow patterns for benefit and cost items, respectively. As can be observed that, under a given cash flow pattern for benefit and cost items different distributional assumptions for project life result in the same final selected project. 
TABLE III. Estimated range of annual benefit and cost values (in $\$ 1000$ - January 1992 prices) and project life for the Cache la Poudre Project

\begin{tabular}{|c|c|c|c|c|c|c|}
\hline \multirow[b]{2}{*}{ Components } & \multicolumn{3}{|c|}{ Alternative 1} & \multicolumn{3}{|c|}{ Alternative 2} \\
\hline & $\mathrm{O}^{2}$ & $\mathrm{M}^{2}$ & $\mathrm{P}^{\mathrm{a}}$ & 0 & $\mathbf{M}$ & $\mathbf{P}$ \\
\hline Project life (years) & 9 & 11 & 13 & 13 & 15 & 17 \\
\hline \multicolumn{7}{|l|}{ Benefits: } \\
\hline 1. Hydropower peaking & - & - & - & 24765.0 & 33020.0 & 41275.0 \\
\hline $\begin{array}{l}\text { 2. Run-of-the river } \\
\text { energy }\end{array}$ & 2269.5 & 2760.0 & 3070.5 & 3655.0 & 4300.0 & 4945.0 \\
\hline $\begin{array}{l}\text { 3. Municipal and indus- } \\
\text { trial water supply }\end{array}$ & 2601.0 & 3060.0 & 3519.0 & 2601.0 & 3060.0 & 3519.0 \\
\hline 4. Imigation & 384.0 & 480.0 & 576.0 & 336.0 & 420.0 & 504.0 \\
\hline 5. Improved management & 125.0 & 250.0 & 375.0 & 125.0 & 250.0 & 375.0 \\
\hline \multicolumn{7}{|l|}{ Costs: } \\
\hline 1. Construction $\operatorname{cost}^{b}$ & 65070.0 & 86760.0 & 108400.0 & 233100.0 & 330200.0 & 412800.0 \\
\hline $\begin{array}{l}\text { 1. Operation, maintenance } \\
\text { and replacement cost }\end{array}$ & 277.5 & 370.0 & 462.5 & 1350.0 & 1800.0 & 2250.0 \\
\hline
\end{tabular}

\begin{tabular}{|c|c|c|c|c|c|c|}
\hline \multirow[b]{2}{*}{ Components } & \multicolumn{3}{|c|}{ Alternative 3} & \multicolumn{3}{|c|}{ Altemative 4} \\
\hline & $\mathrm{O}^{2}$ & $\mathrm{M}^{2}$ & $\overline{\mathrm{P}^{\mathrm{a}} g}$ & $\mathrm{O}$ & $\bar{M}$ & $P$ \\
\hline Project life (years) & 13 & 15 & 17 & 15 & 17 & 19 \\
\hline \multicolumn{7}{|l|}{ Benefits: } \\
\hline 1. Hydropower peaking & 21772.5 & 29030.0 & 36287.5 & 23925.0 & 31900.0 & 39875.0 \\
\hline $\begin{array}{l}\text { 2. Run-of-the river } \\
\text { energy }\end{array}$ & 5015.0 & 5900.0 & 6785.0 & 3230.0 & 3800.0 & 4370.0 \\
\hline $\begin{array}{l}\text { 3. Municipal and indus- } \\
\text { trial water supply }\end{array}$ & 2601.0 & 3060.0 & 3519.0 & 2601.0 & 3060.0 & 3519.0 \\
\hline 4. Irrigation & 328.0 & 410.0 & 492.0 & 304.0 & 380.0 & 456.0 \\
\hline 5. Improved management & 125.0 & 250.0 & 375.0 & 125.0 & 250.0 & 375.0 \\
\hline \multicolumn{7}{|l|}{ Costs: } \\
\hline 1. Construction $\operatorname{cost}^{b}$ & 235600.0 & 313700.0 & 392100.0 & 275000.0 & 366700.0 & 458400.0 \\
\hline $\begin{array}{l}\text { 2. Operation, maintenance } \\
\text { and replacement cost }\end{array}$ & 1095.0 & 1460.0 & 1825.0 & 1215.0 & 1620.0 & 2025.0 \\
\hline
\end{tabular}

From Table IV, the distribution type assumed to each benefit and cost component (with or without considering project life uncertainty) has no significant effect on the mean and standard deviation of the net present value. Tables VIII and IX show the final selcted project(s) under various conditions for uniform and nonuniform cash flow patterns, respectively. For the uniform cash flow pattern, the 
TABLE III. Continued

\begin{tabular}{|c|c|c|c|c|c|c|}
\hline \multirow[b]{2}{*}{ Components } & \multicolumn{3}{|c|}{ Alternative 5} & \multicolumn{3}{|c|}{ Alternative 6} \\
\hline & $\mathrm{O}^{\mathrm{a}}$ & $\mathbf{M}^{\mathbf{2}}$ & $\mathrm{P}^{\mathrm{a}}$ & 0 & $\mathbf{M}$ & $\mathrm{P}$ \\
\hline Project life (years) & 15 & 17 & 19 & 15 & 17 & 19 \\
\hline \multicolumn{7}{|l|}{ Benefits: } \\
\hline 1. Hydropower peaking & 27757.5 & 37010.0 & 46262.5 & 39720.0 & 52960.0 & 66200.0 \\
\hline $\begin{array}{l}\text { 2. Run-of-the river } \\
\text { energy }\end{array}$ & 5074.5 & 5970.0 & 6865.5 & 5848.0 & 6880.0 & 7912.0 \\
\hline $\begin{array}{l}\text { 3. Municipal and indus- } \\
\text { trial water supply }\end{array}$ & 2601.0 & 3060.0 & 3519.0 & 2601.0 & 3060.0 & 3519.0 \\
\hline 4. Irrigation & 264.0 & 330.0 & 396.0 & 312.0 & 390.0 & 468.0 \\
\hline 5. Improved management & 125.0 & 250.0 & 375.0 & 125.0 & 250.0 & 375.0 \\
\hline \multicolumn{7}{|l|}{ Costs: } \\
\hline 1. Construction $\operatorname{cost}^{b}$ & 305700.0 & 407600.0 & 509500.0 & 439300.0 & 585700.0 & 732100.0 \\
\hline $\begin{array}{l}\text { 2. Operation, maintenance } \\
\text { and replacement cost }\end{array}$ & 1365.0 & 1820.0 & 2275.0 & 2002.5 & 2670.0 & 3337.5 \\
\hline
\end{tabular}

\begin{tabular}{|c|c|c|c|c|c|c|}
\hline \multirow[b]{2}{*}{ Components } & \multicolumn{3}{|c|}{ Alternative 7} & \multicolumn{3}{|c|}{ Altemative 8} \\
\hline & $\mathrm{O}^{\mathrm{a}}$ & $\mathbf{M}^{\mathrm{a}}$ & $\mathrm{P}^{\mathbf{a}}$ & $\bar{O}$ & $\bar{M}$ & $\mathbf{P}$ \\
\hline Project life (years) & 13 & 15 & 17 & 9 & 11 & 13 \\
\hline \multicolumn{7}{|l|}{ Benefits: } \\
\hline 1. Hydropower peaking & 18900.0 & 25200.0 & 31500.5 & - & - & - \\
\hline $\begin{array}{l}\text { 2. Run-of-the river } \\
\text { energy }\end{array}$ & 4462.5 & 5250.0 & 6037.5 & 2609.5 & 3070.0 & 3530.5 \\
\hline $\begin{array}{l}\text { 3. Municipal and indus- } \\
\text { trial water supply }\end{array}$ & 2601.0 & 3060.0 & 3519.0 & 2601.0 & 3060.0 & 3519.0 \\
\hline 4. Irrigation & 312.0 & 390.0 & 468.0 & 344.0 & 430.0 & 516.0 \\
\hline 5. Improved management & 125.0 & 250.0 & 375.0 & 125.0 & 250.0 & 375.0 \\
\hline \multicolumn{7}{|l|}{ Costs: } \\
\hline 1. Construction $\operatorname{cost}^{\mathrm{b}}$ & 216300.0 & 288500.0 & 360600.0 & 47910.0 & 63880.0 & 79860.0 \\
\hline $\begin{array}{l}\text { 2. Operation, maintenance } \\
\text { and replacement cost }\end{array}$ & 975.0 & 1300.0 & 1625.0 & 300.0 & 400.0 & 500.0 \\
\hline
\end{tabular}

${ }^{a} \mathrm{O}$ - Optimistic value; $\mathrm{M}$ - Most likely value; $\mathrm{P}$ - Pessimistic value

${ }^{\mathrm{b}}$ Construction cost is the present value.

distributional assumptions for benefit and cost items have no effect on the final selected project (see Table VIII). However, with the nonuniform cash flow pattern the final selected project using a triangular distribution is different from the other distribution assumptions. 
TABLE IV. Comparison of means and standard deviations of NPV ${ }^{a}$ with and without considering project life uncertainty for two selected alternatives ( $\mathrm{T}$ has different distributions

4(a) Alternative 2

\begin{tabular}{|c|c|c|c|c|c|c|}
\hline \multirow{2}{*}{$\begin{array}{l}\text { Distributions } \\
\text { for Benefit \& } \\
\text { Cost Items }\end{array}$} & \multicolumn{2}{|l|}{$\Omega_{T}=0^{b}$} & \multicolumn{2}{|c|}{$\Omega_{T}=5.4 \%^{\mathrm{c}}$} & \multicolumn{2}{|c|}{$\%$ Difference } \\
\hline & $E(N B)$ & Std(NB) & $\mathrm{E}(\mathrm{NB})$ & Std(NB) & $\mathrm{E}(\mathrm{NB})$ & Std(NB) \\
\hline All Normal & $\$ 81,739$ & $\$ 49,832$ & $\$ 81,422$ & $\$ 51,358$ & +0.39 & -2.97 \\
\hline All Lognormal & 82,355 & 49,832 & 82,033 & 51,404 & +0.39 & -3.06 \\
\hline All Gamma & 82,140 & 49,832 & 81,820 & 51,388 & +0.39 & -3.03 \\
\hline All Weibull & 79,684 & 49,832 & 79,377 & 51,255 & +0.39 & -2.78 \\
\hline All Beta & 81,739 & 49,832 & 81,422 & 51,358 & +0.39 & -2.97 \\
\hline All Triangular & 81,739 & 49,832 & 81,422 & 51,356 & +0.39 & -2.97 \\
\hline
\end{tabular}

4(b) Alternative 5

\begin{tabular}{|c|c|c|c|c|c|c|}
\hline \multirow{2}{*}{$\begin{array}{l}\text { Distributions } \\
\text { for Benefit \& } \\
\text { Cost Items }\end{array}$} & \multicolumn{2}{|l|}{$\Omega_{T}=0^{b}$} & \multicolumn{2}{|c|}{$\Omega_{T}=5.4 \%^{c}$} & \multicolumn{2}{|c|}{$\%$ Difference } \\
\hline & $\mathrm{E}(\mathrm{NB})$ & Std(NB) & $\mathrm{E}(\mathrm{NB})$ & $\operatorname{Std}(\mathrm{NB})$ & $\mathrm{E}(\mathrm{NB})$ & Std(NB) \\
\hline All Normal & $\$ 75,761$ & $\$ 57,258$ & $\$ 75,438$ & $\$ 58,379$ & +0.43 & -1.96 \\
\hline All Lognormal & 76,068 & 57,258 & 75,741 & 58,413 & +0.43 & -2.02 \\
\hline All Gamma & 75,961 & 57,258 & 75,635 & 58,401 & +0.43 & -2.00 \\
\hline All Weibull & 74,184 & 57,258 & 73,871 & 58,302 & +0.42 & -1.82 \\
\hline All Beta & 75,761 & 57,258 & 75,438 & 58,379 & +0.43 & -1.96 \\
\hline All Triangular & 75,762 & 58,439 & 75,438 & 59,537 & +0.43 & -1.88 \\
\hline
\end{tabular}

${ }^{2}$ Annual cash flow patterns are all uniform;

${ }^{b}$ Without considering project life uncertainty;

${ }^{c}$ Consider project life uncertainty having a triangular distribution.

From Tables VI, VII, and IX, the final selected project, under the nonuniform cash flow pattern considered, does not vary with the two probability distributions assumed for the net benefit, when all other factors remain the same. However, Hurwicz criterion, under the uniform cash flow pattern, results in different project selection using different distributions for the net present value. For the cases considered, the final selected project by the economic evaluation procedures are consistent except by the Hurwicz criterion.

\section{Summary and Conclusions}

Since uncertainties are involved in bebefit and cost estimations, the conventional economic feasibility test are no longer sufficient. Also, project selection based on the principle of revenue maximization and the likes can no longer be applied straightforwardly. As the uncertainty in economic performance is incorporated, 
ECONOMIC MERIT OF WATER RESOURCE PROJECTS

TABLE V. Comparison of means and standard deviations of NPV with and without considering project life uncertainty for two selected alternatives (T has different distributions

5(a) Alternative 2

\begin{tabular}{|c|c|c|c|c|c|c|}
\hline \multirow{2}{*}{$\begin{array}{l}\text { Distributions } \\
\text { for project } \\
\text { Life }\left(\Omega_{T}\right)\end{array}$} & \multicolumn{2}{|l|}{$\sigma_{T}=0^{b}$} & \multicolumn{2}{|c|}{$\sigma_{T} \neq=0^{c}$} & \multicolumn{2}{|c|}{$\%$ Difference } \\
\hline & $E(N B)$ & $\operatorname{Std}(\mathrm{NB})$ & $\mathrm{E}(\mathrm{NB})$ & Std(NB) & $\mathrm{E}(\mathrm{NB})$ & Std(NB) \\
\hline Normal (5.3\%) & $\$ 53,370$ & $\$ 43,409$ & $\$ 53,264$ & $\$ 44,304$ & +0.20 & -2.06 \\
\hline Uniform & 53,370 & 43,409 & 53,149 & 45,246 & +0.41 & -4.23 \\
\hline Triang $(5.4 \%)$ & 53,370 & 43,409 & 53,267 & 44,345 & +0.19 & -2.16 \\
\hline
\end{tabular}

5(b) Alternative 5

\begin{tabular}{|c|c|c|c|c|c|c|}
\hline \multirow{2}{*}{$\begin{array}{l}\text { Distributions } \\
\text { for project } \\
\text { Life }\left(\Omega_{T}\right)\end{array}$} & \multicolumn{2}{|l|}{$\sigma_{T}=0^{\mathrm{b}}$} & \multicolumn{2}{|c|}{$\sigma_{T} \neq=0^{c}$} & \multicolumn{2}{|c|}{$\%$ Difference } \\
\hline & $E(N B)$ & $\operatorname{Std}(\mathrm{NB})$ & $\mathrm{E}(\mathrm{NB})$ & Std(NB) & $\mathrm{E}(\mathrm{NB})$ & $\mathrm{Std}(\mathrm{NB})$ \\
\hline Normal $(4.7 \%)$ & $\$ 70,354$ & $\$ 44,708$ & $\$ 70,192$ & $\$ 45,528$ & +0.23 & -1.83 \\
\hline Uniform (6.8\%) & 70,354 & 44,708 & 70,018 & 46,402 & +0.48 & -3.79 \\
\hline Triang $(4.8 \%)$ & 70,354 & 44,708 & 70,184 & 45,561 & +0.24 & -1.91 \\
\hline
\end{tabular}

${ }^{a}$ All benefit/cost parameters have triangular distribution;

${ }^{b}$ Without considering project life uncertainty;

${ }^{c}$ Consider project life uncertainty;

${ }^{d}$ Nonuniform cash flow pattern.

TABLE VI. Comparison of results of economic evaluation by different methods and different distributions for project life with triangular distribution for all benefit and cost parameters ${ }^{\mathrm{a}}$

\begin{tabular}{lllll}
\hline Dist'n of & Dist'n of & \multicolumn{3}{l}{ Economic evaluation procedure } \\
\cline { 3 - 5 } project life & net benefit & $\begin{array}{l}\text { Stochastic } \\
\text { dominance }\end{array}$ & EG - CL & $\begin{array}{l}\text { Hurwicz } \\
\text { criterion }\end{array}$ \\
\hline Normal & N & 2 & 2 & 2 \\
& LN & 2 & - & 2 \\
Uniform & N & 2 & 2 & 2 \\
& LN & 2 & - & 2 \\
Triangular & N & 2 & 2 & 2 \\
& LN & 2 & - & 2 \\
\hline
\end{tabular}

${ }^{a}$ Uniform annual cash flow pattern for benefit and cost items.

several conventional ranking criteria based on the largest expected value or meanvariance principle are deficient to evaluate the true project merit.

In this paper, three potentially useful probabilistic approaches, namely, stochastic dominance, expected-gain/confidence limit, and Hurwicz criterion, are considered. The methods are applied to the Cache la Poudre River Basin development 
TABLE VII. Comparison of results of economic evaluation by different methods and different distributions for project life with triangular distribution for all benefit and cost parameters ${ }^{\mathrm{a}}$

\begin{tabular}{lllll}
\hline Dist'n of & Dist'n of \\
project life & net benefit & \multicolumn{3}{l}{ Economic evaluation procedure } \\
\cline { 3 - 5 } & & $\begin{array}{l}\text { Stochastic } \\
\text { dominance }\end{array}$ & EG - CL & $\begin{array}{l}\text { Hurwicz } \\
\text { criterion }\end{array}$ \\
\hline Normal & $\mathrm{N}$ & 5 & 5 & 5 \\
& LN & 5 & - & 5 \\
Uniform & $\mathrm{N}$ & 5 & 5 & 5 \\
& LN & 5 & - & 5 \\
Triangular & $\mathrm{N}$ & 5 & 5 & 5 \\
& LN & 5 & - & 5 \\
\hline
\end{tabular}

${ }^{a}$ Non-uniform annual cash flow pattern for benefit and cost items.

in Colorado for examining the performance of the methods and the sensitivity of several factors that potentially could affect the outcome of the evaluation procedure. These factors include: (1) the distributions of project benefit and cost items, economic performance criteria, and project life and (2) different project evaluation procedures.

The numerical example shows that the results from the procedures based on the stochastic dominance and expected gain-confidence limit criteria are rather insensitive to the distributions of BC or NPV and the distributions of project benefits and cost components. The procedure based on Hurwicz criterion, however, yields different final selection using a triangular distribution from all other distribution considered. Overall speaking, the results from the three probabilistic economic evaluation procedures are quite insensitive to the distribution of benefit and cost items. In practice, accurate estimation of the probability distribution for benefit and cost items is difficult due to the lack of data. This insensitivity of the evaluation results to the distributions relieves the burden on analysts from having to concern with the accuracy of the specified distributions for the economic performance criteria and benefit and cost items. However, the results of evaluation procedure are sensitive to the degree of uncertainty associated with the benefit and cost components.

The consideration of uncertainty of project life results in a decrease in expected net present value and an increase in it variance. However, consideration of project life uncertainty does not affect the final project selection by the three probabilistic economic evaluation procedures.

The proposed procedure for water resource project evaluation considers only the economic efficiency aspect of the project in which project benefits and costs are subject to uncertainty. Water resource project selection and evaluation involve many dimensions and criteria other than economical efficiency alone. The intention of the paper is to suggest a systematic and scientifically sound procedure for project 
TABLE VIII. Comparison of results of economic evaluation by different methods under various conditions with uniform annual cash flow pattern and triangular distribution for project life

\begin{tabular}{|c|c|c|c|c|c|}
\hline \multirow{2}{*}{$\begin{array}{l}\text { Dist'n of benefit } \\
\& \text { cost items }\end{array}$} & \multirow{2}{*}{$\begin{array}{l}\text { Dist'n of } \\
\text { net benefit }\end{array}$} & & \multicolumn{3}{|c|}{ Economic evaluation procedure } \\
\hline & & & $\begin{array}{l}\text { Stochastic } \\
\text { dominance }\end{array}$ & $\mathrm{EG}-\mathrm{CL}$ & $\begin{array}{l}\text { Hurwicz } \\
\text { criterion }\end{array}$ \\
\hline \multirow{5}{*}{ All Normal } & \multirow[t]{3}{*}{$\mathrm{N}$} & $\sigma_{T}=0$ & 2 & 2 & $2(0-.68)$ \\
\hline & & & & & $6(.68-1)$ \\
\hline & & $\sigma_{T} \neq 0$ & 2 & 2 & $\begin{array}{l}2(0-.68) \\
6(.68-1)\end{array}$ \\
\hline & \multirow[t]{2}{*}{ LN } & $\sigma_{T}=0$ & 2 & - & 5 \\
\hline & & $\sigma_{T} \neq 0$ & 2 & - & 5 \\
\hline \multirow[t]{5}{*}{ All Lognormal } & \multirow[t]{3}{*}{$\mathbf{N}$} & $\sigma_{T}=0$ & 2 & 2 & $\begin{array}{l}2(0-.68) \\
6(.68-1)\end{array}$ \\
\hline & & $\sigma_{T} \neq 0$ & 2 & 2 & $2(0-.68)$ \\
\hline & & & & & $6(.68-1)$ \\
\hline & \multirow[t]{2}{*}{ LN } & $\sigma_{T}=0$ & 2 & - & 5 \\
\hline & & $\sigma_{T} \neq 0$ & 2 & - & 5 \\
\hline \multirow[t]{6}{*}{ All Gamma } & \multirow[t]{4}{*}{$N$} & $\sigma_{T}=0$ & 2 & 2 & $2(0-.68)$ \\
\hline & & & & & $6(.68-1)$ \\
\hline & & $\sigma_{T} \neq 0$ & 2 & 2 & $2(0-.68)$ \\
\hline & & & & & $6(.68-1)$ \\
\hline & \multirow[t]{2}{*}{ LN } & $\sigma_{T}=0$ & 2 & - & 5 \\
\hline & & $\sigma_{T} \neq 0$ & 2 & - & 5 \\
\hline \multirow[t]{6}{*}{ All Weibull } & \multirow[t]{4}{*}{$\mathrm{N}$} & $\sigma_{T}=0$ & 2 & 2 & $2(0-.67)$ \\
\hline & & & & & $6(.67-1)$ \\
\hline & & $\sigma_{T} \neq 0$ & 2 & 2 & $2(0-.67)$ \\
\hline & & & & & $6(.67-1)$ \\
\hline & \multirow[t]{2}{*}{$\mathrm{LN}$} & $\sigma_{T}=0$ & 2 & - & 5 \\
\hline & & $\sigma_{T} \neq 0$ & 2 & - & 5 \\
\hline \multirow[t]{6}{*}{ All Beta } & \multirow[t]{4}{*}{$\mathbf{N}$} & $\sigma_{T}=0$ & 2 & 2 & $2(0-.68)$ \\
\hline & & & & & $6(.68-1)$ \\
\hline & & $\sigma_{T} \neq 0$ & 2 & 2 & $2(0-.68)$ \\
\hline & & & & & $6(.68-1)$ \\
\hline & \multirow[t]{2}{*}{$\mathrm{LN}$} & $\sigma_{T}=0$ & 2 & - & 5 \\
\hline & & $\sigma_{T} \neq 0$ & 2 & - & 5 \\
\hline \multirow[t]{5}{*}{ All Triangular } & \multirow[t]{3}{*}{$\mathbf{N}$} & $\sigma_{T}=0$ & 2 & 2 & $2(0-.67)$ \\
\hline & & & & & $6(.67-1)$ \\
\hline & & $\sigma_{T} \neq 0$ & 2 & 2 & $\begin{array}{l}2(0-.67) \\
6(.67-1)\end{array}$ \\
\hline & \multirow[t]{2}{*}{ LN } & $\sigma_{T}=0$ & 2 & - & 5 \\
\hline & & $\sigma_{T} \neq 0$ & 2 & - & 5 \\
\hline
\end{tabular}


TABLE IX. Comparison of results of economic evaluation by different methods under various conditions with uniform annual cash flow pattern and triangular distribution for project life

\begin{tabular}{|c|c|c|c|c|c|}
\hline \multirow{2}{*}{$\begin{array}{l}\text { Dist'n of benefit } \\
\& \text { cost items }\end{array}$} & \multirow{2}{*}{$\begin{array}{l}\text { Dist'n of } \\
\text { net benefit }\end{array}$} & & \multicolumn{3}{|c|}{ Economic evaluation procedure } \\
\hline & & & $\begin{array}{l}\text { Stochastic } \\
\text { dominance }\end{array}$ & $\mathrm{EG}-\mathrm{CL}$ & $\begin{array}{l}\text { Hurwicz } \\
\text { criterion }\end{array}$ \\
\hline \multirow[t]{4}{*}{ All Normal } & $\mathbf{N}$ & $\sigma_{T}=0$ & 2 & 2 & 2 \\
\hline & & & 2 & 2 & 2 \\
\hline & LN & $\sigma_{T}=0$ & 2 & - & 2 \\
\hline & & $\sigma_{T} \neq 0$ & 2 & - & 2 \\
\hline \multirow[t]{4}{*}{ All Lognormal } & $\mathbf{N}$ & $\sigma_{r}=0$ & 2 & 2 & 2 \\
\hline & & & 2 & 2 & 2 \\
\hline & LN & $\sigma_{T}=0$ & 2 & - & 2 \\
\hline & & $\sigma_{T} \neq 0$ & 2 & - & 2 \\
\hline \multirow[t]{4}{*}{ All Gamma } & $\mathrm{N}$ & $\sigma_{T}=0$ & 2 & 2 & 2 \\
\hline & & & 2 & 2 & 2 \\
\hline & LN & $\sigma_{T}=0$ & 2 & - & 2 \\
\hline & & $\sigma_{T} \neq 0$ & 2 & - & 2 \\
\hline \multirow[t]{4}{*}{ All Weibull } & $\mathbf{N}$ & $\sigma_{T}=0$ & 2 & 2 & 2 \\
\hline & & & 2 & 2 & 2 \\
\hline & LN & $\sigma_{T}=0$ & 2 & - & 2 \\
\hline & & $\sigma_{T} \neq 0$ & 2 & - & 2 \\
\hline \multirow[t]{4}{*}{ All Beta } & $\mathbf{N}$ & $\sigma_{T}=0$ & 2 & 2 & 2 \\
\hline & & & 2 & 2 & 2 \\
\hline & LN & $\sigma_{T}=0$ & 2 & - & 2 \\
\hline & & $\sigma_{T} \neq 0$ & 2 & - & 2 \\
\hline \multirow[t]{4}{*}{ All Triangular } & $\mathbf{N}$ & $\sigma_{T}=0$ & 5 & 5 & 5 \\
\hline & & & 5 & 5 & 5 \\
\hline & $\mathbf{L N}$ & $\sigma_{T}=0$ & 5 & - & 5 \\
\hline & & $\sigma_{T} \neq 0$ & 5 & - & 5 \\
\hline
\end{tabular}

selection under economic uncertainty. In doing so, it is hoped that, through the use of the proposed procedure and the likes, much of the confusion and cloud around the evaluation of economic merit of water development projects can be cleared.

\section{Acknowledgements}

This study was supported by the National Science Council of Republic of China and Wyoming Water Resources Center at the University of Wyoming.

\section{References}

Barnes, J. W., Zinn, C. D., and Eldred, B. S.: 1978, A methodology for obtaining the probability density function of the present worth of probabilistic cash flow profiles, AIIE Trans. 10(3), 226-236. 
Baumol, W. J.: 1963, An expected gain-confidence limit criterion for portfolio selection, Management Sci. 10, 174-182.

Bey, R. P.: 1981, The inpact of stochastic project lives on capital budgeting decisions, in R. L. Crum and F. G. J. Derkinderen. (eds.), Capital Budgeting Under Conditions of Uncertainty, Martinus Nijhoff, Boston.

Buck, J. R. and Askin, R. G.: 1986, Partial means in the economic risk analysis of projects, The Engineering Economists 31(3), 189-212.

Bunn, D. W.: 1984, Applied Decision Analysis, McGraw-Hill, New York.

Canada, J. R. and White, J. A.: 1980. Capital Investment Decision Analysis for Management and Engineering, Prentice-Hall, Englewood Cliffs, NJ.

Chen, K. C. W. and Manes, R. P., 1986: A note on Bias in capital budgeting introduced by stochastic life, The Engineering Economist 31(2), 165-174.

El-Ramly, N. A., Peterson, R. E., and Seo, K. K.: 1975, Economic comparison of projects incorporating decision theory and the expected gain-confidence limit criterion, The Engineering Economists 20(1), 61-69.

Grigg, N. S.: 1985, Water Resources Planning, McGraw-Hill, New York.

LaCava, G. J.: 1976, Improving the mean-variance criterion using stochastic dominance, Decision Sci. 7, 29-39.

Markowitz, H.: 1959, Portfolio Selection, Wiley, New York.

Porter, R. B. and Carey, K.: 1974, Stochastic dominance as a risk analysis criterion, Decision Sci. 5, 11-21.

Taha, H. A.: 1976, Operations Research: An Introduction, 2nd edn., MacMillan, New York.

Tufekci, S. and Young, D. B.: 1987, Moments of the present worth of general probabilistic cash flows under random timing, The Engineering Economist 32(4), 303-336.

Tung, Y. K., Wang, P. Y., and Yang, J. C.: 1993, Water resources projects evaluation and ranking under economic uncertainty, J. Water Resour. Mgmt. 7, 311-333.

Van Horne, J. C.: 1972, Capital budgeting under conditions of uncertainty as to project life, The Engineering Economist, 17(3), 189-199.

Young, D. B. and Contreras, L. E.: 1975, Expected present worths of cash flows under uncertain timing, The Engineering Economist, 20(4), 257-268. 